\title{
Physical Education, the Policy Entrepreneur and Comprehensive Schooling: can they exist in harmony?
}

\author{
MALCOLM THORBURN
}

\begin{abstract}
This article analyses the ways in which policy entrepreneurs have recently influenced physical education (PE) policy and practice in England and Scotland and discusses some of the implications this might have for students' learning opportunities within comprehensive schools in future years. And, while considerations of this sort raise a plethora of political, institutional and epistemological questions; the focus of this article is on the role of the policy entrepreneur in shaping policy discussion. This is a relatively new consideration in policy analysis terms, but a critical one in PE at present, given the rise of charitable foundations like the Youth Sport Trust and The Winning Scotland Foundation, and the influence these organisations have of government thinking and action plans.
\end{abstract}

Houlihan \& Green (2006, p. 73) note that, in England, there was 'a palpable sense of relief from physical education (PE) teachers when it was announced in 1991 that PE was to become part of the national curriculum. For a subject which had spent much of its existence at the margins of the curriculum, a more contributory and purposeful future beckoned. Since then the prominence of PE has remained high. Policy developments have committed the government to funding improvements in school facilities as well as creating sport coordinator posts as part of the PE, School Sport and Club Links (PESSCL) strategy (DfES/DCMS, 2003).

During this time the Youth Sport Trust was established as a charitable foundation with a mission to improve the quality of PE and school sport through a variety of initiatives and support programmes. The trust was founded by Sir John Beckwith whose fortune was made through property development and selling international real estate. Sue Campbell as Chairperson and later Chair of the Youth Sport Trust was able to convince government of the link 
between PE, school sport and the achievement of a broad range of affective and educational attainment objectives (Houlihan \& Green, 2006). Recently, the trust has been involved with the creation of 450 specialist sports colleges as well as organising the UK school games since 2006. The Culture Secreatary Andy Burnham has commented that the games: 'are the pinnacle of the school sport system and show how a culture of competition and excellence has been reintroduced to our schools... It's not the eighties any more... PE is not being abandoned from the timetable and competition is no longer a dirty word' (DCMS, 2008).

Policy developments in Scotland have broadly matched those in England with the National Physical Activity Strategy (Scottish Executive, 2003) detailing plans to increase physical activity levels over the next 20 years; a target aided by the recruitment of a staffing network of Active School Coordinators in primary and secondary schools. In addition, the 'Review Group on Physical Education' (Scottish Executive, 2004) recognized the need for better quality PE programmes as the basis for tackling problems with inactivity and lack of interest among students. In June 2004 the Scottish Minister for Education and Young People outlined that PE would receive an exceptional level of support (more curriculum time, more teachers) too address health and active lifestyle priorities.

Up until very recently the prevailing policy view was that it would be misguided and disingenuous to pursue sport-based strategies when such a crisis exists in the basic fitness and movement competence levels of so many school age students. However, as sporting success at national level has the capacity to nourish nationalistic pride it appears that following the May 2007 Scottish Parliamentary elections, when the Scottish National Party (SNP) were returned as the majority partner in a new coalition government, that further changes are afoot. The SNP manifesto for the 2007 election made a commitment to create six regionally based specialist sport academies with entry by application and ability; an innovation which in itself would be something of a challenge to the entitlement for all principles at the heart of the Scottish comprehensive school (McCrone, 2003).

Policy in Scotland has also been affected by charitable organizations seeking to influence curriculum developments in PE and school sport. Most notable among these organizations has been the Winning Scotland Foundation, an independent charity established in 2006, which aims to promote sport as the catalyst for developing positive thinking and for challenging Scots to fulfill their potential by institutionalizing a culture of winning in schools. The foundation was set up by Bill Gammell, a privately educated businessman who is Chairman of Europe's biggest independent oil company. The annual budget of the foundation is in excess of $£ 1 \mathrm{~m}$ per annum, part of which is being used to produce a motivational book to inspire the sporting and business stars of the future. The Scottish government and the Winning Foundation are in talks with local authorities to make the book part of the PE curriculum in secondary schools (MacDonald, 2008). 
The momentum towards winning and adopting a competitive mentality has recently been further fuelled by British success at the Beijing Olympics, with Prime Minister Gordon Brown declaring that there should be a transformation of the sporting culture in schools, with a much greater focus on competition and increases in girls' participation levels. Female Olympic heroes are to lead the campaign for improvements with additional funding being used to help schools meet the Government's target of schools offering five hours of sport a week to all students. The Prime Minister wants to reduce the influence of overly politically correct councils and teachers who consider that competitve sport can be damaging to those who emerge as losers, and who promote instead the benefits of more cooperative and participatory-based experiences. Elite sport merits state involvement as it is considered as a relatively low-cost initiative which has an instrumental value e.g. through reducing health care costs and through improving confidence and self-esteem. For example, Gordon Brown is convinced that investment in school-based competitive sport 'will inspire fitness and help tackle obesity' (Summers, 2008).

A criticism of this view is that related research has had some difficulty in establishing a positive connection between investment in sport and improvements in the health and well-being of the general population (Coalter, 2007). Indeed, the Labour government only a few years previously considered that 'hosting events is not an effective, value for money, method of achieving ... a sustained increase in mass participation' (DCMS/Cabinet Office, 2002). However, it is precisely these ambitions which governments in England and Scotland are now directing attention towards.

In implementing a change agenda, the Youth Sports Trust were assisted by the consensus built around the PESSCL strategy, as it empowered individual schools to decide for themselves whether they wished to gain specialist sports college status or not. Nevertheless, Sue Campbell was considered, based on her background in PE teaching, lecturing and coaching administration, to be helpful in understanding the current work of schools as the basis for achieving policy goals. This is apparent, for example, through its intention to support the National School Sport Week by celebrating achievements in PE and school sport and through recognizing the diversity of needs within schools, see for example, its intention to support students with a range of disabilities. In these types of ways the trust is tackling some of the iniquities which are so apparent in elite sport. For example, over $70 \%$ of the British Olympic team competing at the Beijing Games was educated at independent schools (Hannam, 2008).

By contrast, greater policy contestation in Scotland has created a situation where policy entrepreneurs are often trying to influence practice by working beyond the boundaries of the typical policy community. This situation has arisen, in part, due to Review Group Report on Physical Education reigniting justification-based discussions about how exactly PE and school sport should respond to the interests and changing lifestyles of students. The Chairman's Forward in the Review Group report alluded to the difficulty there was in gaining consensus when it was recorded that many hours were spent in 'robust 
discussion of what is a very complex area' (Scottish Executive, 2004, p. 3). Clearly reaching a form of agreement placed an excessive strain on the policy community and the lack of an ongoing national steering group to monitor the implementation of the Review Group report has made coherent policy progress difficult to achieve. In this environment, teachers traditionally high level of 'continuity and personal relationship within the policy community' (Menter et al, 2004, p. 197) could become eroded unless viable solutions are found to problems exercising the minds of politicians. These problems could become exacerbated further by politicians coming to view the contribution of a policy entrepreneur from outside of the conventional policy process as the best prospect for engineering change. In this respect, it appears of some regret that Scotland has failed so far to find the equivalent of Sue Campbell, or an organisation with similar aspirations to the Youth Sports Trust.

In conclusion, this paper has reported favourably on the sensitized ways in which the Youth Sport Trust has acted to present a range of opportunities for students in schools, which articulate with both comprehensive principles of schooling and which meet (at least for the present time) the political aspirations for improvements in elite sport. Whether this continues in future years with the current governments heightened expectations of the value and benefits of competitive elite sport remains to be seen. However, for the present, a relatively harmonious relationship exists. By contrast, less sensitivity and trust is apparent in Scotland, where there appears to be a growing frustration from some organisations e.g. The Winning Foundation for the health focus in PE, as it has diverted attention away from an excellence and elite sport agenda. An associated problem in this area is the desirability of policy entrepreneurs promoting their particular values through appealing directly to politicians. Whether this approach results in a further erosion of trust between policy makers and teachers remains to be seen. However, at this time, there is some concern that proposals for greater competitive elite sport might not chime particularly well with many of the underpinning values of comprehensive schooling; a model of schooling which has a deeply embedded and enduring resonance with most people in Scotland (McCrone, 2003).

\section{References}

Coalter, F. (2007) A Wider Role for Sport. London: Routledge.

Department for Culture, Media and Sport/Cabinet Office (2002) Game Plan: a strategy for delivering government's sport and physical activity objectives. Strategy Unit. London: DCMS/Cabinet Office.

Department for Culture, Media and Sport (2008) Burnham sets Olympic ambition for school sport Coaching and competition for all in main sports by 2012. http://www.dcms.gov.uk/reference_library/media_releases/5419.aspx

Department for Education and Skills / Department for Culture, Media and Sport. (2003) Learning through Physical Education and Sport: a guide to the physical education, school sport and club links strategy. London: DfeS/DCMS. 
Hannam, L. (2008) Pretty posh and from the shires, Britain's 2008 Beijing Olympic heroes.

http://www.channel4.com/news/articles/society/education/pretty+posh+and+fr om+the+shires+britains $+2008+$ beijing+olympic + heroes $/ 2431167$

Houlihan, B. \& Green, M. (2006) The Changing Status of School Sport and Physical Education: explaining policy change, Sport, Education and Society, 11(1), 73-92.

MacDonald, S. (2008) The tycoon is handing out his treatise on success to every Scottish pupil.

http://www.timesonline.co.uk/tol/news/uk/scotland/article4692350.ece.

McCrone, D. (2003) Culture, Nationalism and Scottish Education: homogeneity and diversity, in T.G.K. Bryce \& W.H. Humes (Eds) Scottish Education. Edinburgh: University of Edinburgh Press.

Menter, I., Mahoney, P. \& Hextall, I. (2004) Never the Twain Shall Meet? Modernising the Teaching Profession in Scotland and England, Journal of Education Policy, 19(2), 179-195.

Scottish Executive (2003) Let's Make Scotland More Active: a strategy for physical activity. Edinburgh: HMSO.

Scottish Executive (2004) The Report of the Review Group on Physical Education. Edinburgh: HMSO.

Summers, D. (2008) Bring Back Competitive School Sports: Brown. http://www.guardian.co.uk/education/2008/aug/25/schoolsports.olympics2012

MALCOLM THORBURN taught in high schools for many years before taking up his current appointment as Lecturer in Physical Education at the University of Edinburgh. He is interested in researching the policy making and policy implementation issues associated with physical education and school sport; in particular, issues of professional change for teachers in terms of curriculum planning and pedagogical practices. Correspondence: Malcolm Thorburn, Moray House School of Education, College of Humanities and Social Sciences, University of Edinburgh, St Leonard's Land, Holyrood Road, Edinburgh EH8 8AQ United Kingdom (malcolm.thorburn@ed.ac.uk). 
